\title{
AVALIAÇÃO DA EFICIÊNCIA DO PROCESSO DE COAGỦLAĈ̃O/FLOCULAČ̃̃O APLICADO AO TRATAMENTO PRIMÁRIO DE EFLUENTE DA INDÚSTRIA PETROQUÍMICA
}

\author{
Felipe Sombra dos Santos ${ }^{1}$ \\ Suzana Morais de Oliveira ${ }^{2}$ \\ Lídia Yokoyama ${ }^{3}$ \\ Magali Christie Cammarota ${ }^{4}$ \\ Diego Macedo Veneu ${ }^{5}$
}

\begin{abstract}
Resumo: Um determinado tipo de efluente de uma indústria petroquímica foi avaliado neste estudo para aplicação em um processo de coagulação, utilizando os coagulantes $\mathrm{FeCl}_{3}, \mathrm{Al}_{2}\left(\mathrm{SO}_{4}\right)_{3}$ e policloreto de alumínio (PAC) no processo de coagulação. Além desses, um polímero aniônico (Magnafloc), também foi utilizado. Durante os ensaios de coagulação/floculação, conduzidos em Jar test, os melhores resultados obtidos com adição de $\mathrm{FeCl}_{3}$ foram alcançados em uma concentração de $300 \mathrm{mg} / \mathrm{L}$ no valor de $\mathrm{pH}$ igual a 9,0, na presença ou não de Magnafloc na concentração de $1,5 \mathrm{mg} / \mathrm{L}$. Sob estas condições obteve-se uma remoção de turbidez de $90 \%$ e $92,8 \%$, e de óleo e graxas de $91,6 \%$ e $86,8 \%$. Já ao utilizar o $\mathrm{Al}_{2}\left(\mathrm{SO}_{4}\right)_{3}$, os melhores resultados foram alcançados a uma concentração de $300 \mathrm{mg} / \mathrm{L}$ em valor de $\mathrm{pH}$ igual a 9,0, também na presença ou não do polímero Magnafloc a uma concentração de $1,0 \mathrm{mg} / \mathrm{L}$. Nestes ensaios a remoção de turbidez foi de $93,5 \%$ e $97,3 \%$, enquanto que a de óleo e graxas foi de $91,5 \%$ e $93,3 \%$. Ao adicionar o PAC, em uma concentração de $150 \mathrm{mg} / \mathrm{L}$ e no valor de $\mathrm{pH}$ igual a 8,0, sem e com adição de Magnafloc na concentração de 1,0 mg/L, os resultados apresentados foram 96,5\% e 98,2\% na remoção de turbidez, e $91,2 \%$ e $95 \%$ na remoção de óleos e graxas. Após a realização de todos os ensaios, concluiu-se que para este determinado tipo de efluente, o PAC (150 $\mathrm{mg} / \mathrm{L})$, em $\mathrm{pH}$ 8,0 e na presença do polímero aniônico Magnafloc $(1,0 \mathrm{mg} / \mathrm{L})$ se apresentou como a melhor escolha para o tratamento, por promover a melhor remoção de turbidez $\mathrm{e}$ óleos e graxas.
\end{abstract}

Palavras-Chave: Coagulação, floculação, turbidez, óleos e graxas.

Abstract: One type of effluent in a petrochemical industry has been reported in this study for application in a coagulation process, using $\mathrm{FeCl}_{3}, \mathrm{Al}_{2}\left(\mathrm{SO}_{4}\right)_{3}$ and aluminum polychloride (PAC) coagulant in the coagulation process. In addition to these, an anionic polymer (Magnafloc) was also used. During the test the coagulation / flocculation carried out in Jar test, the best results were obtained with the addition of $\mathrm{FeCl}_{3}$ were achieved at a concentration of $300 \mathrm{mg} / \mathrm{L}$ at $\mathrm{pH}=9.0$, in the presence or absence of the concentration of Magnafloc $1.5 \mathrm{mg} / \mathrm{L}$. Under these conditions gave a turbidity removal of $90 \%$ and $92.8 \%$, and oil and grease $91.6 \%$ and $86.8 \%$. Already when using $\mathrm{Al}_{2}\left(\mathrm{SO}_{4}\right)_{3}$, the best results were achieved at a concentration of $300 \mathrm{mg} / \mathrm{L}$ at $\mathrm{pH}=9.0$, also in the presence or absence of Magnafloc polymer at a concentration of $1.0 \mathrm{mg} / \mathrm{L}$. In these tests the removal of turbidity was $93.5 \%$ and $97.3 \%$, while that of oil and grease was $91.5 \%$ and $93.3 \%$. By adding the PAC in a concentration of $150 \mathrm{mg} / \mathrm{L}$ and equal to the value of $\mathrm{pH} 8.0$ with and without addition of Magnafloc concentration of $1.0 \mathrm{mg} / \mathrm{L}$, the results were $96.5 \%$ and $98.2 \%$ turbidity removal and $91.2 \%$ and $95 \%$ removal of oil and grease. After conducting all the tests, it was concluded that for this particular type of effluent, the PAC $(150 \mathrm{mg} / \mathrm{L})$ at $\mathrm{pH}$ 8.0 and in the presence of anionic polymer Magnafloc $(1.0 \mathrm{mg} / \mathrm{L})$ are presented as the best choice for the treatment, by promoting better turbidity removal and oils and greases.

${ }^{1}$ EQ/UFRJ, Escola de Química da Universidade Federal do Rio de Janeiro. E-mail: fpsombra@ig.com.br 
Key-words: Coagulation, flocculation, turbidity, oils and greases.

\section{INTRODUÇÃO}

Os efluentes industriais, geralmente, possuem elevadas concentrações de poluentes orgânicos e inorgânicos, podendo conter poluentes tóxicos (Nasr, 2007, Kurniawan, 2006, Benvenuti, 2012). Um exemplo são as indústrias petroquímicas e refinarias de petróleo que demandam grandes volumes de água para as suas atividades, e, como consequência, resulta na geração de grandes quantidades de efluentes que podem conter óleo ou outros contaminantes químicos. As principais fontes de incorporação de efluentes oleosos em rios ou córregos são provenientes de vazamentos, transporte, estações de transbordo e dos processos que envolvem o refino. Estes incluem soluções ácidas, soda exausta, águas de lavagem do petróleo cru e dos derivados, água proveniente da etapa de dessalinização, os condensados resultantes da retificação a vapor e da destilação, assim como da limpeza ou regeneração com vapor dos catalisadores de processo (Mariano, 2005).

Os processos convencionais aplicados em refinarias, indústrias e estações de tratamento de efluentes, muitas vezes não são possíveis de remover estes contaminantes em níveis desejados (Moursy e Abo El-Ela, 1982, Rattanapan, 2011).

Diferentes tipos de tratamentos são voltados para cada classe de poluente, encontrados em um efluente de um processo industrial. $\mathrm{O}$ tratamento físicoquímico primário, que engloba processos, tais como, coagulação, floculação, precipitação química, flotação e decantação, permitem a redução de alguns parâmetros ligados principalmente a matéria orgânica particulada e finamente particulada que representa boa parte das partículas coloidais (Nunes, 2008; Braile, 1993; Metcalf \& Eddy, 2004).
Nas décadas de 1970 e 1980 foram desenvolvidos métodos de preparação de compostos poliméricos de ferro e alumínio, coagulantes amplamente difundidos na Europa, Estados Unidos e Japão, conhecidos como "polímeros inorgânicos", usados com sucesso no tratamento de águas com temperaturas baixas e brandas para coagulação de partículas e moléculas responsáveis pela turbidez e cor. A adoção de qualquer tipo de coagulante deve-se necessariamente, ser precedido de estudos de tratabilidade que realmente confirmem a vantagem de seu uso (Di Bernardo, 2005; Wang e Tang, 2001).

Os testes de jarro (Jar test) usando reagentes químicos inorgânicos $\mathrm{e}$ orgânicos vêm sendo conduzidos para determinar a melhor condição operacional na etapa de coagulação/floculação, conduzindo a remoções satisfatórias de óleos, sólidos, turbidez e cor (Tanik, 2002; Yuan, 2006; Mayer, 2008, Silvan, 2012, Nam, 2013).

Coagulantes inorgânicos e poliméricos tais como os sais de alumínio e de ferro, por razões econômicas e por apresentarem uma maior valência são muito utilizados. Dentre estes sais, o sulfato de alumínio $\left(\mathrm{Al}_{2}\left(\mathrm{SO}_{4}\right)_{3}\right)$, o cloreto férrico $\left(\mathrm{FeCl}_{3}\right)$ e o policloreto de alumínio (PAC) são os mais utilizados (Zouboulis, 2005; Di Bernardo, 2005).

O objetivo deste trabalho é analisar as remoções de turbidez e óleo e graxas de um efluente proveniente da indústria petroquímica, empregando o método de tratamento por coagulação/floculação, avaliando-se três tipos diferentes de coagulante e um floculante através das variações de concentração e dos valores de $\mathrm{pH}$. A partir dos resultados obtidos, será definido o ensaio que apresentou as melhores remoções para ser implementados no tratamento primário para este tipo de efluente em questão. 


\section{MATERIAIS E MÉTODOS}

Os reagentes utilizados foram o $\mathrm{FeCl}_{3}$ e $\mathrm{Al}_{2}\left(\mathrm{SO}_{4}\right)_{3}$ da VETEC, o policloreto de alumínio (PAC) Fongrafloc 029 da Clariant e o polímero aniônico Magnafloc da Ciba Specialty Chemicals Pty.

Os ensaios foram realizados em béckers com capacidade de 1,0 L cada, com auxílio de um Jar-Test modelo 2286LDB da Nova Ética equipado com 6 provas e 6 agitadores tipo paleta. Os efeitos do tipo de coagulante, concentrações dos coagulantes, $\mathrm{pH}$ e floculante sobre os parâmetros turbidez e óleo e graxas foram realizados para determinar as condições ótimas de remoção. As amostras utilizadas nos ensaios foram coletadas pela empresa, no tanque de equalização da planta petroquímica, e enviado para o laboratório, através de bombonas. Ao iniciar o ensaio de coagulação com essas amostras fornecidas, elas foram homogeneizadas dentro da bombona e colocadas nos béqueres da plataforma do Jar Test a uma temperatura de $25^{\circ} \mathrm{C}$ e volume de $0,5 \mathrm{~L}$.

Segundo Di Bernardo (2005), durante a etapa de coagulação, a velocidade de agitação era mantida em 200 rpm a um tempo de coagulação de 1,0 minuto com concentrações prédeterminadas dos coagulantes $\mathrm{FeCl}_{3}$, $\mathrm{Al}_{2}\left(\mathrm{SO}_{4}\right)_{3}$ e $\mathrm{PAC}$, variando os valores de $\mathrm{pH}$ na faixa de 5,0 a 9,0, pois nesta faixa o ambiente é menos agressivo, tanto quanto alcalino, quanto ácido. $\mathrm{Na}$ etapa de floculação sem adição de polímero, a velocidade de agitação era mantida em $40 \mathrm{rpm}$ a um tempo de floculação de 20 minutos.

$\mathrm{Na}$ etapa de adição do polímero, as mesmas condições anteriores eram mantidas, sendo somente, introduzido as concentrações de polímero na faixa de 0,5 a 3,0 mg/L. Ao término do tempo de floculação, as amostras eram submetidas a um tempo de sedimentação dos flocos de 15 minutos. Este tempo de floculação foi conduzido ainda dento da plataforma do Jar Test, no volume de béquer já mencionado.

Antes e após os ensaios de coagulação/floculação as amostras ensaiadas eram analisadas para quantificar o teor de turbidez e de óleo e graxas. Todas as análises citadas foram realizadas de acordo com as metodologias analíticas, descritas no Standard Methods for the Examination of Water and Wastewater.

\section{RESULTADOS E DISCUSSÕES}

\subsection{Origem e Caracterização do Efluente}

O efluente gerado pelas indústrias petroquímicas é recebido e armazenado, pela empresa, em três células abertas ao ar livre, com capacidade de $100 \mathrm{~m}^{3} /$ cada. Através de um sistema de bombeio seletivo, a fase oleosa sobrenadante é enviada para tanques de armazenamento de óleo e, em seguida, enviada para outra empresa que a reprocessa. O efluente composto da fase aquosa é encaminhado para tanques de armazenamento que alimentam uma Estação de Tratamento de Efluentes (ETE). Já a borra que fica no fundo das células desta ETE, é retirada de forma programada por meio de dragagem. Para isso, é necessário esvaziar a célula. Depois a borra é encaminhada para o destino adequado. Além de receber os efluentes oleosos, a ETE também trata efluentes sanitários, provenientes de pequenas empresas, que não possuem sistemas de tratamento próprios. Os resultados médios obtidos pelos ensaios de caracterização da amostra do efluente, recebido são apresentados na Tabela 1 .

Quando os parâmetros são comparados com os padrões estabelecidos pela Resolução do CONAMA 430 de 13 de maio de 2011, DZ-205 e NT-202 (INEA) observa-se que, o valor de $\mathrm{pH}$, se encontra perto da neutralidade, o que já favorece a tratabilidade do mesmo, uma vez que no processo de coagulação/floculação o 
efluente geralmente apresenta bons resultados em valores de $\mathrm{pH}$ na faixa de neutro a moderadamente alcalino. Segundo os padrões estabelecidos, o pH de lançamento deste efluente deve estar na faixa de 5,0 a 9,0, conforme é citado na Tabela 1.

Tabela 1. Caracterização do Efluente

\begin{tabular}{|c|c|c|}
\hline Parâmetro & Resultado & VMP \\
\hline $\mathrm{pH}$ & 6,8 & $5-9$ \\
\hline $\begin{array}{l}\text { DQO } \\
{[\mathrm{mg} / \mathrm{L}]}\end{array}$ & $8.283,5$ & \\
\hline $\begin{array}{c}\mathrm{DBO} \\
{[\mathrm{mg} / \mathrm{L}]}\end{array}$ & $4.187,5$ & 120,0 \\
\hline $\begin{array}{l}\mathrm{O \& G} \\
{[\mathrm{mg} / \mathrm{L}]}\end{array}$ & 681,8 & 50,0 \\
\hline $\begin{array}{c}\mathrm{ST} \\
{[\mathrm{mg} / \mathrm{L}]}\end{array}$ & $49.598,5$ & \\
\hline $\begin{array}{c}\mathrm{STF} \\
{[\mathrm{mg} / \mathrm{L}]}\end{array}$ & $36.335,0$ & \\
\hline $\begin{array}{c}\mathrm{STV} \\
{[\mathrm{mg} / \mathrm{L}]}\end{array}$ & $13.263,5$ & \\
\hline $\begin{array}{l}\text { Nitrogênio total } \\
{[\mathrm{mg} / \mathrm{L}]}\end{array}$ & 65,5 & 20,0 \\
\hline $\begin{array}{l}\text { Fósforo total } \\
{[\mathrm{mg} / \mathrm{L}]}\end{array}$ & 6,9 & \\
\hline $\begin{array}{l}\text { Fenóis } \\
{[\mathrm{mg} / \mathrm{L}]}\end{array}$ & $2.816,0$ & 0,5 \\
\hline $\begin{array}{l}\text { Cloretos } \\
{[\mathrm{mg} / \mathrm{L}]}\end{array}$ & $77.038,5$ & \\
\hline $\begin{array}{c}\text { Turbidez } \\
\text { [uT] }\end{array}$ & 454,0 & \\
\hline
\end{tabular}

Segundo o American Petroleum Institute (API), as fontes de acidez e alcalinidade nos efluentes deste segmento são provenientes da destilação, dos produtos intermediários, tratamentos ácidos, craqueamento catalítico, limpeza de equipamentos, tratamento cáustico dos destilados, adoçamento e purificação de gases ácidos, no controle de corrosão e nas unidades de refrigeração da planta.

De acordo com Mariano (2005), muitos efluentes das operações de refino têm alta concentração de DBO e/ou DQO. De fato, os valores observados de DBO e DQO se encontram em concentrações bem acima das médias descritas na literatura (Braile, 1993;
Wieczorek, 2005). Tal observação pode estar associada, em parte, pela parcela do efluente oriundo de esgotamento sanitário, das empresas citadas.

As recomendações pela legislação em vigor, INEA e CONAMA, para lançamento de efluente em relação aos parâmetros DBO e DQO são de concentrações menores que $120 \mathrm{mg} / \mathrm{L}$ e $250 \mathrm{mg} / \mathrm{L}$, respectivamente.

Outro parâmetro que se encontra com valores bem elevados, mesmo quando comparado com efluentes de indústrias deste segmento é o de Óleo e Graxas. Segundo Braile (1993), este parâmetro geralmente encontra-se na faixa de 23 a $200 \mathrm{mg} / \mathrm{L}$, tendo o mesmo a necessidade de redução para uma concentração $\leq 20$ $\mathrm{mg} / \mathrm{L}$ para ser lançado em corpo receptor.

Para os parâmetros voltados para os sólidos, pode-se tomar como base $\mathrm{o}$ limite de materiais sedimentáveis que não deve exceder $1 \mathrm{~mL} / \mathrm{L}$ (Teste no Cone Imnhoff) no efluente tratado. E, segundo Mariano (2005), muitas das operações deste tipo de segmento geram efluentes contendo sólidos dissolvidos e em suspensão, em concentrações que podem chegar a valores na faixa de 50 a $100 \mathrm{mg} / \mathrm{L}$.

Para os parâmetros nitrogênio e fenóis, os limites estabelecidos são de 20 $\mathrm{mg} / \mathrm{L}$ e $0,2 \mathrm{mg} / \mathrm{L}$, respectivamente. $\mathrm{O}$ nitrogênio é gerado em unidades de refrigeração que utilizam amônia e na conversão do nitrogênio durante o craqueamento catalítico. Segundo Braile (1993), a concentração de nitrogênio total pode chegar a valores de aproximadamente $120 \mathrm{mg} / \mathrm{L}$. Compostos fenólicos são habitualmente presentes em efluentes de refinarias, geralmente aparecem como solutos presentes em produtos finais e resultantes de reações químicas.

Os parâmetros fósforo, cloretos e turbidez não são descritos nestas normativas, mas são extremamente 
importantes, pois estão relacionados com problemas como redução de atividade fotossintética, número de espécies e organismos (turbidez), eutrofização de corpos aquáticos (fósforo) e, toxicidade para organismos aquáticos e até dificultar alguns processos de tratamento pela elevada salinidade (cloretos). Segundo Braile (1993), a concentração média de cloretos pode variar de 19 a $1080 \mathrm{mg} / \mathrm{L}$ e de fósforo pode chegar a valores de $97 \mathrm{mg} / \mathrm{L}$ para este tipo de efluente.

\subsection{Coagulação com $\mathrm{FeCl}_{3}$}

$\mathrm{Na}$ Figura 1 pode-se observar o efeito da adição do coagulante $\mathrm{FeCl}_{3}$ sobre o parâmetro turbidez em diferentes valores de $\mathrm{pH}$. De modo geral, em todas as concentrações em estudo, o aumento do valor de $\mathrm{pH}$ mostrou-se benéfico na remoção de turbidez. No $\mathrm{pH} 5,0$, foram observados os valores mais elevados de turbidez, correspondendo a 139 uT, 106 uT e 89 uT para as concentrações de 100 $\mathrm{mg} / \mathrm{L}, \quad 300 \mathrm{mg} / \mathrm{L}$ e $500 \mathrm{mg} / \mathrm{L}$, respectivamente. Já no $\mathrm{pH}$ 9,0 foram alcançados os menores valores, correspondendo a 86,5 uT, 45,4 uT e 3 uT para as concentrações de $100 \mathrm{mg} / \mathrm{L}$, $300 \mathrm{mg} / \mathrm{L}$ e $500 \mathrm{mg} / \mathrm{L}$, respectivamente.

Nas concentrações de $300 \mathrm{mg} / \mathrm{L}$ e $500 \mathrm{mg} / \mathrm{L}$ os resultados obtidos de turbidez apresentam-se próximos quando comparados entre seus respectivos valores de $\mathrm{pH}$. Para o $\mathrm{pH} 8,0$, o valor de 46,8 uT corresponde a um percentual de remoção de turbidez de $89,7 \%$ (concentração de $300 \mathrm{mg} / \mathrm{L}$ ) e o valor de 55,1 uT corresponde a uma percentual de remoção de 87,9\% (concentração de 500 $\mathrm{mg} / \mathrm{L}$ ). Como já visto acima, para o $\mathrm{pH}$ 9,0 foi observado o valor de 45,4 uT e 36 uT, correspondendo aos percentuais de remoção de $90 \%$ e de $92,1 \%$ para as concentrações de $300 \mathrm{mg} / \mathrm{L}$ e $500 \mathrm{mg} / \mathrm{L}$, respectivamente.

\subsection{Coagulação com $\mathrm{Al}_{2}\left(\mathrm{SO}_{4}\right)_{3}$}

A Figura 2 apresenta os resultados obtidos para o coagulante $\mathrm{Al}_{2}\left(\mathrm{SO}_{4}\right)_{3}$ sobre o parâmetro turbidez em diferentes valores de $\mathrm{pH}$. Na concentração de 300 $\mathrm{mg} / \mathrm{L}$, observa-se que é obtido um valor de turbidez de 75,3 uT para o valor de pH 5,0. A partir deste, os valores de turbidez tem um leve incremento nos valores de $\mathrm{pH}$ de 6,0 e 7,0, correspondendo à turbidez de 78,5 uT e $83,7 \mathrm{uT}$, respectivamente. A partir do $\mathrm{pH}$ 7,0 , os valores de turbidez decrescem rapidamente atingindo o valor de 54,4 uT para o $\mathrm{pH} 8,0$ e de 29,4 uT para o $\mathrm{pH}$ 9,0 , onde se encontra o valor mais representativo de remoção $(93,5 \%)$.

Comportamento semelhante é observado na concentração de $600 \mathrm{mg} / \mathrm{L}$ que no valor de $\mathrm{pH}$ de 5,0, a turbidez é de 47,9 uT e este valor eleva-se para 67,8 uT no pH 6,0. No pH 7,0 e 8,0, os valores de turbidez praticamente se mantêm estáveis, correspondendo a valores na faixa entre 50 a $60 \mathrm{uT}$. No $\mathrm{pH}$ 9,0 é observado o menor valor de turbidez (13,8 uT) que corresponde a um percentual de remoção de $97 \%$.

\subsection{Coagulação com Policloreto de Alumínio (PAC)}

$\mathrm{Na}$ Figura 3 são apresentados os resultados obtidos com a adição do coagulante PAC sobre o parâmetro turbidez em diferentes valores de $\mathrm{pH}$. $\mathrm{Na}$ concentração de $150 \mathrm{mg} / \mathrm{L}$, os valores de turbidez decrescem lentamente de $81 \mathrm{uT}$ no $\mathrm{pH}$ 5,0 até o valor de 70,5 uT no $\mathrm{pH}$ 7,0 . Em seguida, estes valores decrescem rapidamente atingindo os valores de 16 uT para o $\mathrm{pH}$ 8,0 e de 19,7 uT para o $\mathrm{pH}$ 9,0 . Pode-se constatar que os melhores resultados foram obtidos no $\mathrm{pH} \mathrm{8,0} \mathrm{e}$ 9,0 , correspondendo aos percentuais de remoção de $96,5 \%$ e $95,7 \%$, respectivamente. $\mathrm{Na}$ concentração de $300 \mathrm{mg} / \mathrm{L}$, o valor mais elevado de turbidez (76,5 uT) é observado no valor de $\mathrm{pH}$ igual a 5,0.

Já nos valores de $\mathrm{pH}$ de 6,0 e 7,0 pode-se observar que os valores de turbidez permanecem bem próximos, mantendo-se na faixa de 65 uT a $70 \mathrm{uT}$. No $\mathrm{pH} 8,0$ o valor de turbidez atinge 
53,3 uT e no pH 9,0 o valor é de 27,5 $\mathrm{uT}$, correspondendo ao maior percentual de remoção $(93,9 \%)$.

\subsection{Coagulação / Floculação com $\mathrm{FeCl}_{3}$ / Magnafloc, $\mathrm{Al}_{2}\left(\mathrm{SO}_{4}\right)_{3}$ / Magnafloc e PAC / Magnafloc}

A Figura 4 mostra os resultados de turbidez obtidos com adição do polímero Magnafloc como auxiliar na floculação em diferentes concentrações utilizandose como coagulantes o $\mathrm{FeCl}_{3}$ na concentração de $300 \mathrm{mg} / \mathrm{L}$ e pH 9,0, o $\mathrm{Al}_{2}\left(\mathrm{SO}_{4}\right)_{3}$ na concentração de $300 \mathrm{mg} / \mathrm{L}$ e $\mathrm{pH}$ igual a 9,0, e o PAC na concentração de $150 \mathrm{mg} / \mathrm{L}$ e $\mathrm{pH}$ igual a 8,0 .

Pode-se observar que a adição do polímero aniônico Magnafloc reduziu os valores de turbidez encontrados na etapa de coagulação de ambos os coagulantes. Com a introdução do polímero, não houve uma redução significativa na turbidez, quando comparada somente com o coagulante. A turbidez obtida foi de 39,4 uT para o coagulante $\mathrm{FeCl}_{3}$, de 15,3 uT para o coagulante $\mathrm{Al}_{2}\left(\mathrm{SO}_{4}\right)_{3}$ e de 15,3 uT para o coagulante $\mathrm{Al}_{2}\left(\mathrm{SO}_{4}\right)_{3}$ e de 13,5 uT para o coagulante PAC, correspondente às concentrações de 0,5 $\mathrm{mg} / \mathrm{L}, \quad 0,5 \quad \mathrm{mg} / \mathrm{L} \quad$ e $\quad 3,0 \quad \mathrm{mg} / \mathrm{L}$, respectivamente.

Os melhores resultados de turbidez foram alcançados com a adição do coagulante $\mathrm{FeCl}_{3}$ em pH 9,0 com 1,5 $\mathrm{mg} / \mathrm{L}$ de Magnafloc, correspondendo a 32,6 uT e a um percentual de remoção de $92,8 \%$. Com o coagulante $\mathrm{Al}_{2}\left(\mathrm{SO}_{4}\right)_{3}$, em pH 9,0 e com adição de 1,0 mg/L de Magnafloc, a turbidez correspondeu a 12,2 uT e a um percentual de remoção de $97,3 \%$. Já com adição de PAC, em $\mathrm{pH}$ 8,0 e com adição de $1,0 \mathrm{mg} / \mathrm{L}$ de Magnafloc, a turbidez correspondeu a 8,3 uT e a um percentual de remoção de $98,2 \%$.

$\mathrm{Na}$ Figura 5 é possível de se comparar os resultados obtidos para o parâmetro óleo e graxas nos ensaios que apresentaram os melhores resultados de remoção de turbidez descritos acima. Pode-se observar que a remoção de óleo e graxas foi fortemente influenciada pela redução da turbidez do efluente, indicando a existência de óleos e graxas no material particulado.

Os ensaios com adição de $\mathrm{FeCl}_{3}$, $\mathrm{Al}_{2}\left(\mathrm{SO}_{4}\right)_{3}$ e PAC apresentaram os melhores resultados bem similares de óleo e graxas, correspondendo aos valores de $57 \mathrm{mg} / \mathrm{L}, 58 \mathrm{mg} / \mathrm{L}$ e $60 \mathrm{mg} / \mathrm{L}$ e a percentuais de remoção de aproximadamente $92 \%$. O ensaio com adição de $\mathrm{FeCl}_{3}(300 \mathrm{mg} / \mathrm{L})$, Magnafloc $(1,5 \mathrm{mg} / \mathrm{L})$ e $\mathrm{pH}$ igual a 9,0 , foi o que apresentou o valor de óleo e graxas mais elevado (90 mg/L), correspondendo a uma remoção de $86,8 \%$.

Os ensaios que apresentaram os melhores resultados foram os que utilizaram $\mathrm{Al}_{2}\left(\mathrm{SO}_{4}\right)_{3} \quad(\mathrm{mg} / \mathrm{L}) \quad+$ Magnafloc (mg/L) e PAC (mg/L) + Magnafloc (mg/L), correspondendo aos valores de óleo e graxas de 45,5 mg/L e $34 \mathrm{mg} / \mathrm{L}$, e os percentuais de remoção de $93,3 \%$ e $95 \%$, respectivamente. 


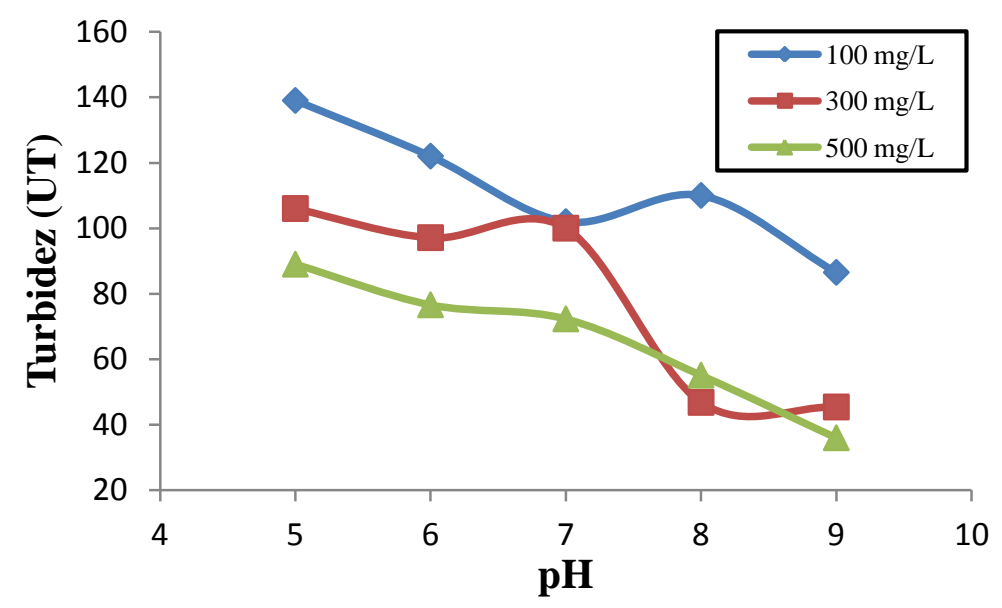

Figura 1. Efeito da concentração de $\mathrm{FeCl}_{3}$ na remoção de turbidez

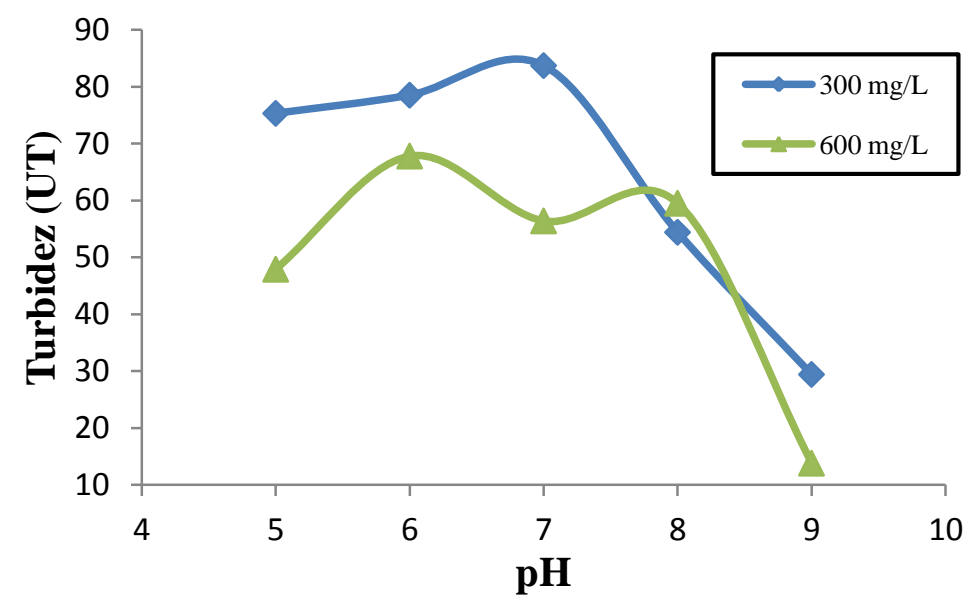

Figura 2. Efeito da concentração de $\mathrm{Al}_{2}\left(\mathrm{SO}_{4}\right)_{3}$ na remoção de turbidez

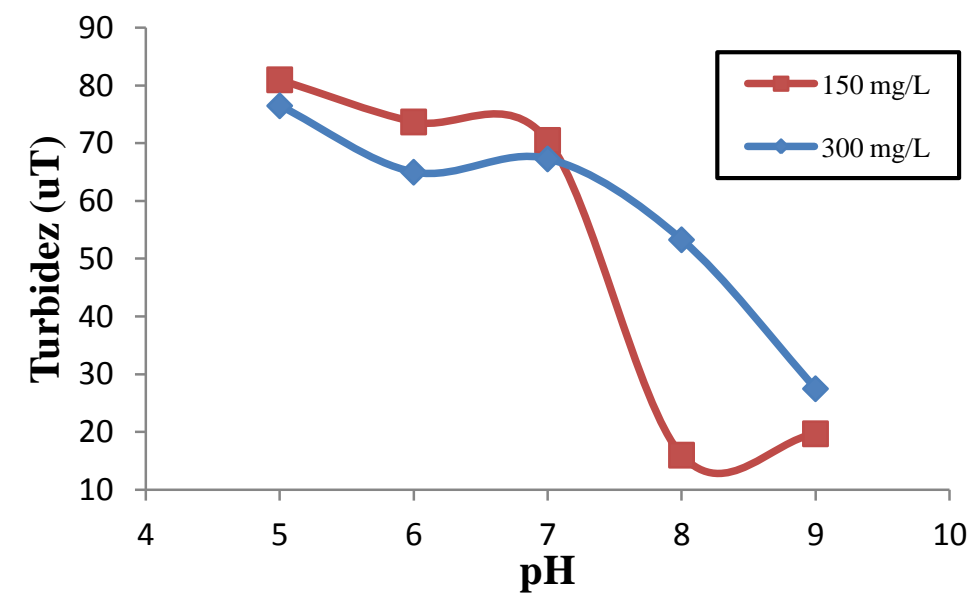

Figura 3. Efeito da concentração de PAC na remoção de turbidez 


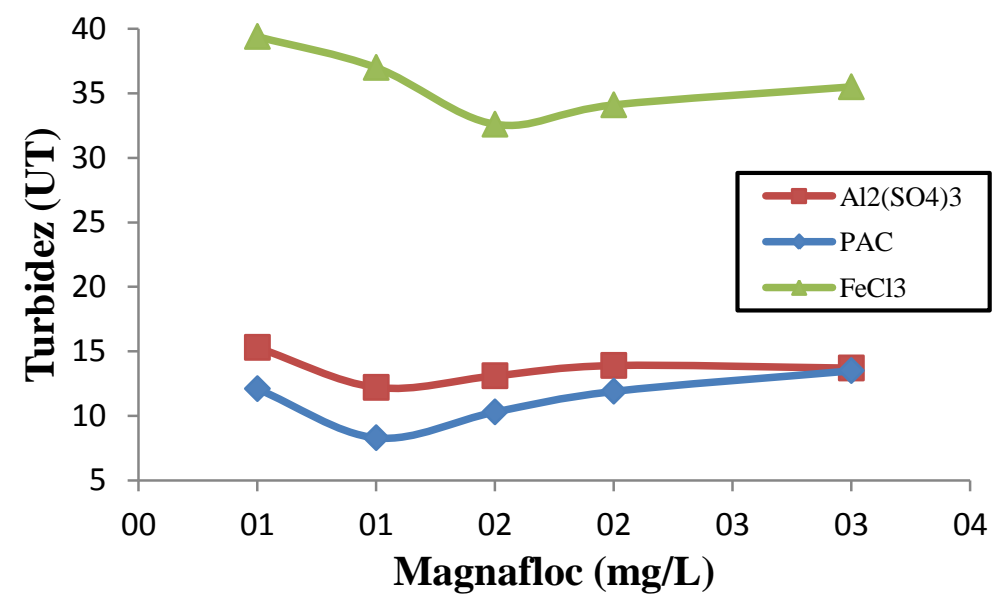

Figura 4. Efeito da concentração de $\mathrm{FeCl}_{3}$ / Magnafloc, $\mathrm{Al}_{2}\left(\mathrm{SO}_{4}\right)_{3} /$ Magnafloc e PAC / Magnafloc na remoção de turbidez

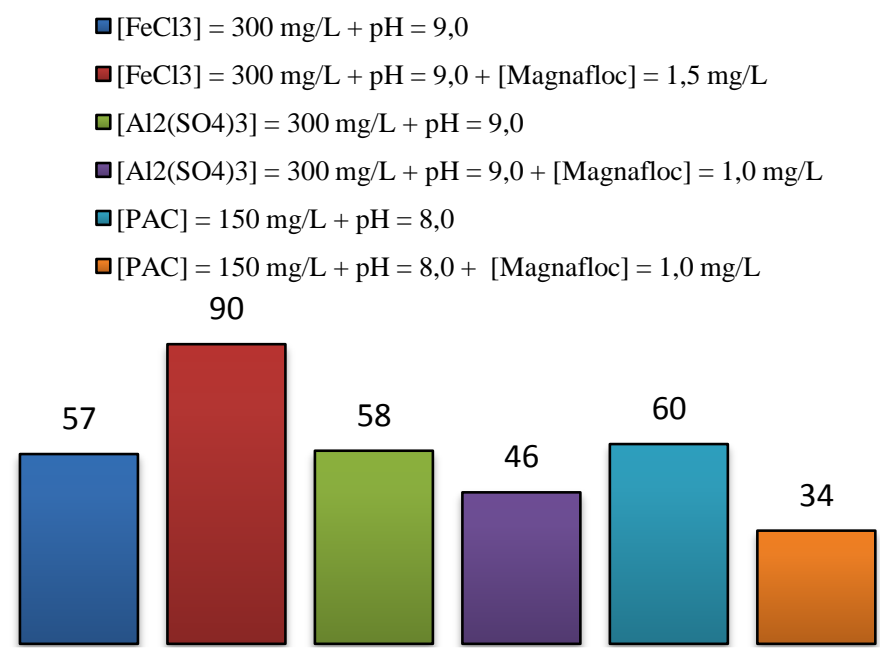

Figura 5. Resultados de Óleo e Graxas para os Diferentes Ensaios (mg/L)

\section{CONCLUSÕES}

Os ensaios de clarificação pelo processo de coagulação e floculação foram efetivos na remoção da turbidez e de óleos e graxas.

Nos ensaios de coagulação/ floculação, os melhores resultados com adição de $\mathrm{FeCl}_{3}$ foram alcançados a uma concentração de $300 \mathrm{mg} / \mathrm{L}$ e pH 9,0, sem e com adição de Magnafloc a uma concentração de $1,5 \mathrm{mg} / \mathrm{L}$, correspondendo a uma remoção de turbidez de $90 \%$ e $92,8 \%$, e de óleo e graxas de $91,6 \%$ e $86,8 \%$.
Já com o $\mathrm{Al}_{2}\left(\mathrm{SO}_{4}\right)_{3}$, os melhores resultados foram alcançados a uma concentração de $300 \mathrm{mg} / \mathrm{L}$ e pH 9,0, sem e com adição de Magnafloc a uma concentração de $1,0 \mathrm{mg} / \mathrm{L}$, correspondendo a uma remoção de turbidez de $93,5 \%$ e $97,3 \%$, e de óleo e graxas de $91,5 \%$ e $93,3 \%$.

Os resultados com PAC a uma concentração de $150 \mathrm{mg} / \mathrm{L}$ e pH 8,0, sem e com adição de Magnafloc a uma concentração de $1,0 \mathrm{mg} / \mathrm{L}$, foram obtidos os valores de remoção de turbidez correspondente a $96,5 \%$ e $98,2 \%$, e de óleo e graxas de $91,2 \%$ e $95 \%$. 
Após comparação dos coagulantes e na presença ou ausência de polímero, o melhor resultado foi obtido utilizando o PAC $(150 \mathrm{mg} / \mathrm{L})$, em $\mathrm{pH} 8,0$ e na presença do polímero aniônico Magnafloc (1,0 $\mathrm{mg} / \mathrm{L})$. Sob essas condições é possível concluir, conforme os objetivos citados, que a utilização destes reagentes permitiu uma melhor remoção dos parâmetros abordados neste estudo, para este tipo de efluente em questão.

\section{REFERÊNCIAS}

AMERICAN

PETROLEUM

INSTITUTE - API Acesso em 15 de junho de 2013: http://www.api.org

BENVENUTI, T., RODRIGUES, M. A. S., ZIULKOSKI, A. L., BERNARDES, A. M., FERREIRA, J. Z., Tratamento de efluentes de eletrodeposição de níquel por fotoeletrooxidação. 2012. Revista da Escola de Minas, 65 (3), 349-356, Ouro Preto.

BRAILE, P. M., CAVALCANTI, J. E. W. A. 1993. Manual de Tratamento de Águas Residuárias Industriais, $2^{\mathrm{a}}$ edição. CETESB, São Paulo.

DI BERNARDO, L.; DANTAS, A. DI BERNARDO. 2005. Métodos e técnicas de tratamento de água, vol. 1, 2ª edição, ed. Rima, São Carlos, SP.

KURNIAWAN, T. A., CHAN, G. Y. S., LO, W., BABEL, S., Physico-chemical treatment techniques for wastewater laden with heavy metals. 2006. Chemical Engineering Journal, 118, 83-98.

MARIANO, J. B. 2005. Impactos ambientais do refino de petróleo, Rio de Janeiro: Interciência.

MAYER, B. K., RYU, H., ABBASZADEGAN, 2008. M. Treatability of U. S. Environmental Protection Agency Contaminant Candidate List Viruses: Removal of Coxsackievirus and Echovirus using
Enhanced Coagulation, Environmental Science Technology, 42, 6890-6896.

METCALF \& EDDY. 2004. Wastewater Engineering Treatment and Reuse, $4^{\mathrm{a}}$ ed., ed. Mc Graw Hill.

MOURSY, A. S., ABO EL-ELA, S. E. 1982. Treatment of oily refinery wastes using a dissolved air flotation process, Environrnent lnternational, 7, 267-270.

NASR, F., DOMA, H. S. 2007. Chemical industry wastewater treatment, Environmentalist, 27, 275-286.

NUNES, J. A. 2008. Tratamento Físico Químico de Águas Residuárias Industriais, $5^{\text {a }}$ ed., Info Graphics Gráfica $\&$ Editora, Aracaju.

RATTANAPAN, C., SAWAIN, A., SUKSAROJ, T., SUKSARO, C. 2012. Enhanced efficiency of dissolved air flotation for biodiesel wastewater treatment by acidification and coagulation processes, Desalination, 280 (1-3), 370-377.

SILVAN, R. S., CANEPA, J. R. L., BARAJAS, J. R. H. 2012. Mezclas con potencial coagulante para clarificar aguas superficiales, Rev. Int. Contam. Ambient., 28 (3), 229-236.

TANIK, A., GENCELI, E. A., EKDAL, A. 2002. Chemical treatability of dairy wastewater, Environmental Management and Health, 13 (2), $163-174$.

NAM, S., JO, B., KIM, M., KIM, W., $\mathrm{ZOH}$, K., 2013. Streaming current titration for coagulation of high turbidity water, Colloids and Surfaces A: Physicochemical and Engineering Aspects, 419 (20), 133-139.

WANG, D., TANG, H. Modified inorganic polymer flocculant - PFSi: its preparation, characterization and coagulation behavior. 2001. Water Research, 35 (14), 3418 - 3428. 
WIECZOREK, A., ANGELIS, D. F., FURLAN, L. T., CORRÊA JR., B. 2005. Melhoria na qualidade da água pela implantação de um novo sistema de tratamento de efluente industrial na refinaria Replan/Petrobras, Holos Environmental, 5 (1), p. 23 . Brasil.

YUAN, Y., WEN, Y., LI, X., LUO, S. 2006. Treatment of wastewater from dye manufacturing industry by coagulation,
Journal of Zhejiang University Science A, 7 (2) $340-344$.

ZOUBOULIS, A., TRASKAS, G. 2005. Comparable evaluation of various commercially available aluminiumbased coagulants for the treatment of surface water and for the post-treatment of urban wastewater, Journal of Chemical Technology and Biotechnology, 80, 1136 - 1147. 